\title{
Soil Fertility Evaluation to Adopt Climate-Smart Agriculture in Mambattu Village, Maduranthakam Block of Kanchipuram District, Tamil Nadu, India
}

\author{
Kalpana Palani†, Selva Preetha Paneer Selvam, Sathya Velusamy and \\ Ramasubramaniyan Ramanathan Melmangalam \\ National Agro Foundation, Research and Development Centre, Anna University Taramani Campus, Taramani, \\ Chennai-600113, India \\ †Corresponding author: Kalpana Palani; kalpana.rajesh@nationalagro.org
}

Nat. Env. \& Poll. Tech Website: www.neptjournal.com

Received: 22-05-2020

Revised: 20-07-2020

Accepted: $25-07-2020$

Key Words:

Soil fertility

Agriculture

Lean farming

Climate change

Sustainable agriculture

\begin{abstract}
Assessment of soil fertility is essential to help identify strategies for sustainable agricultural production systems that decrease the negative environmental impact. The objective of this research study is to carry out a preliminary assessment of soil fertility status to adopt climate-smart agriculture to address the climate change challenges that adversely affect crop productivity and livelihoods of the farming community. The research was carried out in Mambattu village, Maduranthakam block of Kanchipuram district, Tamil Nadu. A systematic set of twenty geo-referenced soil samples were collected from the study village using GPS (Global Positioning System) and analysed for $\mathrm{pH}$, EC, available macro, secondary and micronutrients to develop a credible soil fertility index (SFI). The preliminary fertility data of Mambattu village revealed that the $\mathrm{pH}$ of soil samples varied from acidic to alkaline with about $40 \%$ as neutral while the electrical conductivity showed non-saline and medium status of Organic Carbon (OC). The soil samples were predominantly sufficient in $\mathrm{N}$ and some micro nutrients (Fe, $\mathrm{Mn}$ ), while medium in $\mathrm{S}$ and $\mathrm{B}$ and deficient in $\mathrm{P}, \mathrm{K}, \mathrm{Ca}, \mathrm{Mg}, \mathrm{Zn}$ and $\mathrm{Cu}$. Results from initial studies indicate that practices like site specific nutrient management, green manuring, use of organic inputs, use of integrated pest management, seed treatment etc., have a high potential for implementing climate-smart agricultural technologies. Soil fertility evaluation can be an efficient tool to improve soil health which can positively impact crop productivity and be one of the important climate-smart technologies practices adopted by the farmers.
\end{abstract}

\section{INTRODUCTION}

The rural community in India is dependent on agriculture and allied sectors for their livelihoods, either directly as a farmer (own or leased lands) or indirectly as an agricultural labourer (landless). Thus, the agriculture sector provides employment to more than $60 \%$ of the Indian population people, which is much more than any other economic sector.

Climate change, which is attributable to the natural climate cycle and anthropogenic activities, has adversely affected agricultural productivity the world over including in India. As large parts of arable land in India are rain-fed, agriculture depends on the rainfall. Thus, rainfed agriculture as largely practised in India will be adversely affected by an increase or decrease in the overall rainfall range but also by the shifts in the timing of the rainfall. Due to increased variation in the rainfall as a combination of many factors including climate change, farm productivity is impacted adversely and this has a serious implication on both food production and the country's food security.
The impact of climate change on water availability will be particularly severe for India because large parts of the country already suffering from water scarcity, to begin with, and are largely dependent on groundwater for irrigation. According to Cruz et al. (2007), India's wetlands and ecosystems are severely degraded due to the decline in precipitation and increased drought conditions. About 54 percent of India faces high to extremely high water stress (Shiao et al. 2015).

The Climate-Smart Agriculture (CSA), a concept initiated by FAO to respond to the combined challenges of climate change and their potential threat to food security; has brought out a rich, resourceful and comprehensive approach to mitigate the risk of climate change. According to the FAO, three main approaches to mitigate climate change include a sustainable increase of agricultural productivity, adaptation and building resilience to climate change and reduction of GHG emissions. Beyond technological solutions, many other practices are both cost-effective and have a positive climatic impact, such as better manure management, integrated crop-livestock management, use of renewable energy, use 
of legumes or cover crops, improved animal feeding, and practices that increase soil carbon (Kalpana et al. 2019).

Soil fertility is one of the important factors affecting the yields of the crops. In order to achieve sustainable agriculture production, soil characterization for fertility evaluation of a particular region or area is important. In recent years, due to the imbalanced and inadequate fertilizer use, coupled with low efficiency of other inputs, the response (production) efficiency of chemical fertilizer nutrients has declined tremendously under intensive agriculture. In fact, poor growth, declining yield, pest and disease infestations associated with poor soil fertility are the major threats to marginal farmers of India (Raghunatha Reddy et al. 2019)

Hence, maintaining soil health and sustaining agricultural productivity is a major concern for many farmers. Despite good care and a lot of investments, the farmer is not able to get a reasonable return. Lack of knowledge on periodic soil testing for any nutrient deficiency and seeking the right advice from experts are some of the reasons for declining soil fertility, agricultural productivity and loss to farmers. Though huge information on soil fertility status of soil at the district and state level is available, the village level fertility evaluation is very low in India. Hence, village level soil fertility indexing would be beneficial in understanding the distributions of soil properties at the field scale for refining agricultural management practices and assessing the impact of agriculture on environmental quality (Cambardella et al. 1994). In addition, maintaining or improving the soil quality can provide economic benefits in the form of increased productivity, efficient use of inputs, and improvement in water and air quality. Assessment of soil quality involves measuring physical, chemical and biological soil properties and using these measured values to evaluate changes in the soil as a result of land-use change or management practices (Adolf 2012).

\section{STUDY AREA}

Mambattu is a small village/hamlet among the ninety-five villages in Vaiyavoor Panchayath, Maduranthakam block, in the rural region of Kanchipuram district of Tamil Nadu (Fig. 1). It is surrounded by Lathur block towards north, Thirukkazhukunram block towards east, Acharapakkam block towards west, Chithamur block towards the south. It lies between $12^{\circ} 28^{\prime} \mathrm{N}$ and $79^{\circ} 83^{\prime} \mathrm{E}$ and receives an annual rainfall of $1228.5 \mathrm{~mm}$ and a mean annual temperature of $38^{\circ} \mathrm{C}$. The total geographical area of the taluk is 332.43 ha, while the total area under cultivation is approximately 63.271 ha. According to the Census 2011, the village has 209 families with a total population of 803 , with a literacy of $41 \%, 55.2 \%$ employed individual and $44.8 \%$ non-working.

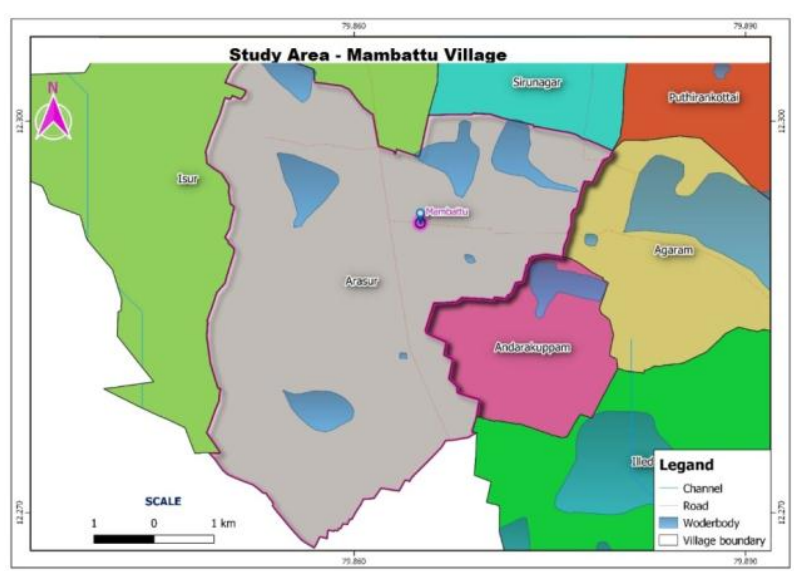

Fig. 1: Study Area - Mambattu village, Maduranthakam block, Kanchipuram district, Tamil Nadu, India.

Of the $55.2 \%$ working individual, $6.1 \%$ of individuals are cultivators (owner or co-owner) and $52.8 \%$ are agricultural labourers. This emphasizes the need to support agriculture through climate agriculture technologies and practices as close to $60 \%$ of the population is dependent on agriculture directly or indirectly for their livelihoods. Maduranthakam block is dominated by red soil with sandy loam texture, with major crops cultivated include paddy, sugarcane, maize, ragi, groundnut and coconut. The major sources of irrigation are wells and canal.

The main objective of the study was to explore how Climate Smart Agriculture technological innovations could solve climate-mediated problems in agriculture at the village level. Hence, preliminary work on soil fertility indexing studies was undertaken in the study location to understand the soil fertility status currently. Reassessment of the impact of interventions of the above implemented technology is planned to be carried out in the future.

\section{MATERIALS AND METHODS}

\section{Collection of Soil Samples}

As an initial step, soil samples were collected for assessing the health status of the soil. In total, 20 geo-referenced surface soil samples from the agricultural fields of the research village were collected using GPS (Global Positioning System) at $0-30 \mathrm{~cm}$ depth by adopting the standard procedures of soil sample collection. The collected soil samples were air-dried, gently crushed, sieved using a $2 \mathrm{~mm}$ sieve for all analysis except organic matter analysis wherein the sample was sieved using a $0.5 \mathrm{~mm}$ sieve. The processed soil samples were preserved in polythene bags for further analysis. 
Table 1: Fertility Rating Class and Nutrient Index Value.

\begin{tabular}{|lll|}
\hline S. No. & Nutrient Index & Value \\
\hline 1 & Low & $<1.67$ \\
2 & Medium & $1.67-2.33$ \\
3 & High & $>2.33$ \\
\hline
\end{tabular}

\section{CHEMICAL ANALYSIS OF SOIL SAMPLES}

The chemical analysis of the soil samples of all the sites was carried out following standard procedures as per the guide to laboratory establishment for plant nutrient analysis as indicated by FAO (2008) and Tandon (2005).

The Nutrient Index Values were calculated using the following formula:

$$
\mathrm{NIV}=[(\mathrm{PH} \times 3)+(\mathrm{PM} \times 2)+(\mathrm{PL} \times 1)] / 100
$$

Where, NIV is Nutrient Index Value, PL, PM and PH are the percentage of soil samples falling in the category of low, medium and high nutrient status and which are given weightage of one, two and three respectively (Ramamoorthy \& Bajaj 1969). The fertility ratings and corresponding index values are given in Table 1.

\section{RESULTS AND DISCUSSION}

\section{Physico-chemical Properties}

The result pertaining to the percent sample category and nutrient index of physico chemical properties of Mambattu village is given in the Table. 2 . The $\mathrm{pH}$ is an important index of soils that determines the extent of the acidity/ alkalinity and directly influences agriculture productivity. The $\mathrm{pH}$ value reflects the integrated effect of the acid-base reactions taking place in the soil system (Mokolobate \& Haynes 2002).

The sample soil in the research showed a wide range of $\mathrm{pH}$ between 5.53-8.51 with a mean value of 6.92. Moreover, samples showing acidic, neutral and alkaline $\mathrm{pH}$ are 35, 40 and 25 per cent respectively with fertility index indicating neutral $\mathrm{pH}$. Most of the soils require the application of organic manures for improvement in the physical condition of the soil as well as for improvement in soil health. EC $(\mathrm{mS} / \mathrm{cm})$ of the research field ranged from $0.04-0.38 \mathrm{mS} / \mathrm{cm}$ i.e., less than $0.8 \mathrm{mS} / \mathrm{cm}$, which is within the normal range.

Organic matter has an essential role in agricultural soil, as it supplies plant nutrients, improves the soil structure, improves water infiltration and retention, feeds soil microflora and fauna, and the retention and cycling of applied fertilizer (Johnston 1986). In the study area, organic carbon is low in $40 \%$ of soils, medium in $40 \%$ soils, and high in $20 \%$ of soils. The range of organic carbon in the soil ranges between $0.39-1.09$ per cent, with an average mean value of 0.67, which indicates medium fertility index.

\section{Available Macro Nutrients}

The results of the percent sample category and nutrient index of macronutrients of Mambattu village are furnished in Table 3. The nitrate content of the soil ranged from 15.0-39.7 $\mathrm{mg} / \mathrm{kg}$ with a mean value of $25.66 \mathrm{mg} / \mathrm{kg}$, where 90 per cent soil falls under high, 10 percent under medium with no soil sample showing low nitrate category (Fig. 2). Hence, the fertility index of nitrate content of Mambattu soil is high.

The fertility index of phosphorus availability in soils revealed that the phosphorus content is low in acidic soil

Table 2: Percent sample category and nutrient index of the physico-chemical properties of Mambattu village.

\begin{tabular}{|lllllllll}
\hline S. No. & Parameters & Percent samples & & Range & Mean \pm SD & Nutrient Index Value & Fertility Index \\
\hline 1 & pH & Acidic & Neutral & Alkaline & $5.53-8.51$ & $6.92 \pm 0.55$ & 1.90 & Neutral \\
& & 35 & 40 & 25 & & & & \\
2 & EC $(\mathrm{mS} / \mathrm{cm})$ & Harmless & Normal & Harmful & $0.04-0.38$ & $0.15 \pm 0.09$ & 1.00 & Harmless \\
& & 100 & 0 & 0 & & & & \\
3 & OC $(\%)$ & Low & Medium & High & $0.39-1.09$ & $0.67 \pm 0.19$ & 1.80 & \\
& & 40 & 40 & 20 & & & & Medium \\
\hline
\end{tabular}

Table 3: Percent sample category and nutrient index of macronutrients of Mambattu village.

\begin{tabular}{|c|c|c|c|c|c|c|c|c|}
\hline \multirow{2}{*}{$\begin{array}{l}\text { S. } \\
\text { No. }\end{array}$} & \multirow[t]{2}{*}{ Parameters } & \multicolumn{3}{|c|}{ Percent samples } & \multirow[t]{2}{*}{ Range } & \multirow[t]{2}{*}{ Mean \pm SD } & \multirow{2}{*}{$\begin{array}{l}\text { Nutrient } \\
\text { Index Value }\end{array}$} & \multirow{2}{*}{$\begin{array}{l}\text { Fertility } \\
\text { Index }\end{array}$} \\
\hline & & Low & Medium & High & & & & \\
\hline 1 & Available Nitrogen $(\mathrm{mg} / \mathrm{kg})$ & 0 & 10 & 90 & $15.0-39.7$ & $25.66 \pm 5.82$ & 2.90 & High \\
\hline 2 & Available Phosphorus (Acidic soil) (mg/kg) & 100 & 0 & 0 & $8.93-85.79$ & $28.71 \pm 24.70$ & 1.00 & Low \\
\hline 3 & Available Phosphorus (Alkalin esoil) (mg/kg) & 44.4 & 22.2 & 33.3 & $5.81-71.28$ & $24.84 \pm 21.32$ & 1.89 & Medium \\
\hline 4 & Available Potassium (mg/kg) & 75 & 0 & 25 & $50.0-257.0$ & $116.10 \pm 61.55$ & 1.50 & Low \\
\hline
\end{tabular}




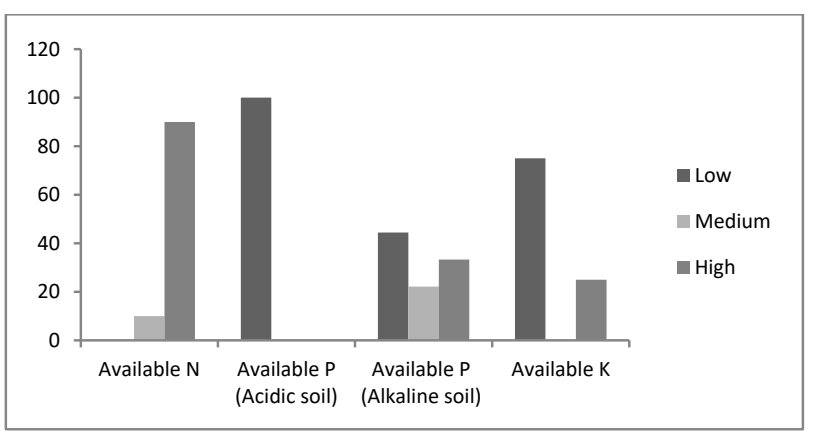

Fig. 2: Fertility rating of macronutrients.

and medium in alkaline soil. The percent sample category of acidic soil shows that the $100 \%$ samples fall under the low category where phosphorus content ranges from 8.93-85.79 $\mathrm{mg} / \mathrm{kg}$ with an average of $28.71 \mathrm{mg} / \mathrm{kg}$. The percent sample category of phosphorus content of alkaline soil shows that the 44.4, 22.2 and 33.3 percent falls under low, medium and high respectively with content ranging between 5.81-71.28 $\mathrm{mg} / \mathrm{kg}$ with a mean value of $24.84 \mathrm{mg} / \mathrm{kg}$. Similarly, the potassium content of the soil ranged from $50.0-257.0 \mathrm{mg} / \mathrm{kg}$, with a mean value of $116.10 \mathrm{mg} / \mathrm{kg}$ where the fertility index denotes the soil is low in potassium with 75 percent samples falling under low and the rest under the high category.

The results are significantly influenced by the farming practices of farmers in this region. Most of the farmers are using chemical fertilizers-urea and phosphatic fertilizers only, which contains concentrated amounts of nitrogen and organic carbon, potassium and phosphorus. On the basis of these results of the study, the farmers were advised to use integrated nutrient management practices to maintain optimum levels of all the essential nutrients for plants. Singh \& Mishra (2012) reported a similar impact in their study that the low to medium fertility status for nitrogen, phosphorus, potassium and sulphur was due to the imbalanced and insufficient fertilizer use, along with low efficiency of other inputs. The response (production) efficiency of chemical fertilizer has reduced extremely under intensive agriculture (Kalpana et al. 2019).

\section{Available Secondary Nutrients}

The results of the percent sample category and fertility index of secondary nutrients of Mambattu village are presented

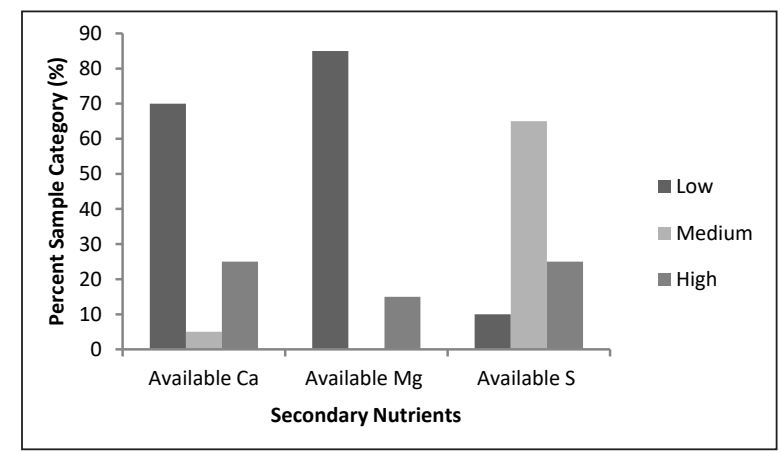

Fig. 3: Fertility rating of secondary nutrients.

in Table 4. The fertility index of calcium, magnesium and sulphur were low, low and medium respectively. The available calcium content of soil ranged from 458-3869 mg/ $\mathrm{kg}$ with a mean value of $1492.50 \mathrm{mg} / \mathrm{kg}$, where 70 percent of samples come under the low category (Fig. 3). Similarly, the magnesium content of the soil ranged from $192-893 \mathrm{mg} /$ $\mathrm{kg}$ with a mean value of $386.20 \mathrm{mg} / \mathrm{kg}$, where 85 percent of samples were under the low category. The low category of calcium and magnesium in the soil is due to acidic $\mathrm{pH}$. In the study village, the $\mathrm{pH}$ of the maximum number of samples was acidic to near neutral. Hence, these soils require high liming material to neutralize the soil acidity and supply $\mathrm{Ca}$ and $\mathrm{Mg}$. The choice of suitable liming material based on the content of soil $\mathrm{Ca}$ and $\mathrm{Mg}$ is a key to provide crops and soils with an adequate quantity of these nutrients. The aim of a liming program is to institute preferred soil $\mathrm{pH}$ and to sustain soil fertility levels with an optimum range of $\mathrm{Ca}$ and $\mathrm{Mg}$. Other reason for the low levels of $\mathrm{Ca}$ might be attributed to the continuous addition of acidifying chemical fertilizers. Similar results were recorded by Amara et al. (2015). Moreover, the sulphur content of the soil ranged between 18.9-60.6 $\mathrm{mg} / \mathrm{kg}$ with an average value of $28.21 \mathrm{mg} / \mathrm{kg}$, where 65 percent of samples falls under the medium category. From the results, it is confirmed that the soils of all the sites are likely to respond to sulphur fertilization. Similar results were also obtained by Kumar et al. (2011). The medium levels of available sulphur in the soils of the study area might be due to lack of sulphur addition and continuous removal of $\mathrm{S}$ by crops (Balanagoudar 1989).

Table 4: Percent sample category and nutrient index of secondary nutrients of Mambattu village.

\begin{tabular}{|c|c|c|c|c|c|c|c|c|}
\hline \multirow[t]{2}{*}{ S. No. } & \multirow[t]{2}{*}{ Parameters } & \multicolumn{3}{|c|}{ Percent samples } & \multirow[t]{2}{*}{ Range } & \multirow[t]{2}{*}{ Mean \pm SD } & \multirow{2}{*}{$\begin{array}{l}\text { Nutrient Index } \\
\text { Value }\end{array}$} & \multirow{2}{*}{$\begin{array}{l}\text { Fertility } \\
\text { Index }\end{array}$} \\
\hline & & Low & Medium & High & & & & \\
\hline 1. & Available Calcium (mg/kg) & 70 & 5 & 25 & $458-3869$ & $1492.50 \pm 1074.93$ & 1.55 & Low \\
\hline 2. & Available Magnesium (mg/kg) & 85 & 0 & 15 & $192-893$ & $386.20 \pm 207.93$ & 1.30 & Low \\
\hline 3. & Available Sulfur (mg/kg) & 10 & 65 & 25 & $18.9-60.6$ & $28.21 \pm 9.12$ & 2.15 & Medium \\
\hline
\end{tabular}


Table 5: Percent sample category and nutrient index of micronutrients of Mambattu village.

\begin{tabular}{|c|c|c|c|c|c|c|c|c|}
\hline \multirow{2}{*}{$\begin{array}{l}\text { S. } \\
\text { No. }\end{array}$} & \multirow[t]{2}{*}{ Parameters } & \multicolumn{3}{|c|}{ Percent samples } & \multirow[t]{2}{*}{ Range } & \multirow[t]{2}{*}{ Mean \pm SD } & \multirow{2}{*}{$\begin{array}{l}\text { Nutrient } \\
\text { Index Value }\end{array}$} & \multirow{2}{*}{$\begin{array}{l}\text { Fertility } \\
\text { Index }\end{array}$} \\
\hline & & Low & Medium & High & & & & \\
\hline 1 & Available Zinc (mg/kg) & 100 & 0 & 0 & $0.88-2.40$ & $1.48 \pm 0.38$ & 1.00 & Low \\
\hline 2 & Available Manganese (mg/kg) & 40 & 15 & 45 & $2.26-49.12$ & $19.62 \pm 14.55$ & 2.05 & Medium \\
\hline 3 & Available Iron (mg/kg) & 10 & 15 & 75 & $5.39-167.14$ & $45.01 \pm 43.73$ & 2.65 & High \\
\hline 4 & Available Copper (mg/kg) & 80 & 20 & 0 & $0.79-3.09$ & $1.89 \pm 0.66$ & 1.20 & Low \\
\hline 5 & Available Boron (mg/kg) & 15 & 85 & 0 & $0.70-1.20$ & $0.92 \pm 0.14$ & 1.85 & Medium \\
\hline
\end{tabular}

\section{Available Micronutrients}

The results of the percent sample category and nutrient index of micronutrients of Mambattu village are furnished in Table 5. The available zinc content ranged between 0.88 $2.40 \mathrm{mg} / \mathrm{kg}$ with a mean value of $1.48 \mathrm{mg} / \mathrm{kg}$, whereas the available manganese content of the soil ranged between $2.26-49.12 \mathrm{mg} / \mathrm{kg}$ with a mean value of $19.62 \mathrm{mg} / \mathrm{kg}$. Moreover, the available iron content of the soil ranged between $5.39-167.14 \mathrm{mg} / \mathrm{kg}$ with a mean value of $45.01 \mathrm{mg} /$ $\mathrm{kg}$. Similarly, the available copper content of soil ranged between $0.79-3.09 \mathrm{mg} / \mathrm{kg}$ with a mean value of $1.89 \mathrm{mg} / \mathrm{kg}$, while boron ranged from $0.70-1.20 \mathrm{mg} / \mathrm{kg}$ with an average value of $0.92 \mathrm{mg} / \mathrm{kg}$.

From these values, it can be inferred that the maximum percent sample category of zinc, manganese, iron, copper and boron fall under low, high, high, low and medium category respectively (Fig. 4). However, the fertility index of micronutrient content of Mambattu soil showed that zinc and copper were low, whereas the manganese and boron seem to be medium, while the iron was high. Similar results were noticed by Pandiaraj et al. (2017). Soils with an acidic $\mathrm{pH}$ range lead to higher solubility and could result in higher availability of $\mathrm{Fe}$ content. Thus, acidic soils contain a high range of iron, which is supported by the findings of Khadka et al. (2016) and Methe et al. (2012).

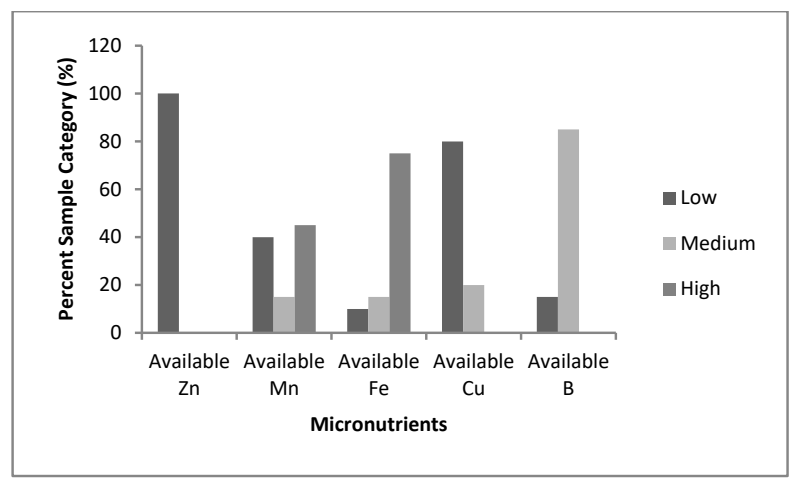

Fig. 4: Fertility rating of micronutrients.

\section{CONCLUSION}

The soil fertility index of the Mambattu village revealed that the $\mathrm{pH}$ of the soil varied from acidic to alkaline with a major percentage falling under neutral; while the Electrical Conductivity, an indicator of the soluble salt content of the soil is normal. The organic carbon status is medium. The available $\mathrm{N}, \mathrm{P}$ and $\mathrm{K}$ were high, low and low in status, while secondary nutrients like $\mathrm{Ca}, \mathrm{Mg}$ and $\mathrm{S}$ were low, low and medium status respectively. With regard to micronutrients, the soil is sufficient in $\mathrm{Fe}$ and $\mathrm{Mn}$, while $\mathrm{Zn}$ and $\mathrm{Cu}$ are deficient and the boron is intermediate.

Hence, the village is categorized as soil with intermediate fertility status. However, for sustaining agriculture productivity and improving soil fertility status from sufficient to a high level, the most limiting factors controlling the soil fertility that were identified suggested corrective and conservation practices to achieve long-term sustainable production. Thus, the preliminary assessment of the soil fertility status of Mambattu village by using a soil index was used as one of the key information to improve the strategies and effective techniques towards sustainable agriculture. This also strengthens the basic information, the ability to formulate workable solutions towards sustainable crop production and the adoption of best management practices.

Hence, the approach incorporates the evaluation of climate-smart technologies, practices, services, and processes relevant to local climatic risk management. It also identifies opportunities for maximizing adaptation gains associated with local knowledge and further development plans. It also aims to reach out to farmers to adopt knowledge-based practices in order to boost fertility status. These may include practices such as site-specific nutrient management, increased use of organic nutrient sources, sustainable land use and cropping systems, and appropriate strategic agronomic practices. In future, soil fertility evaluation will be undertaken after two or three years in the same village which can be considered as an efficient tool to quantify the impact of climate-smart technologies provided to the farmers along with other crop improvement practices and management strategies to overcome the challenges of climate change. 


\section{REFERENCES}

Amara, D. M. K., Massaquoi, S. D. A. and Patil, P. L. 2015. Assessment of spatial variability of soil properties in the hot semi-arid northern transition zone of India through remote sensing and geographic information system (GIS). AshEse Journal of Agricultural Sciences, 1: 43-53.

Adolf, V.I., Shabala, S., Andersen, M.N., Razzaghi, F. and Jacobsen, S.E. 2012. Varietal differences of quinoa's tolerance to saline conditions. Plant and Soil, 357(1-2): 117-129.

Balanagoudar, A.B. 1989. Investigation on status and forms of sulphur in soils of North Karnataka. M. Sc. (Agri.) Thesis.

Cambardella, C. A., Moorman, T. B., Parkin, T. B., Karlen, D. L., Novak, J. M., Turco, R. F. and Konopka, A. E. 1994. Field-scale variability of soil properties in central Iowa soils. Soil Science Society of America Journal, 58(5): 1501-1511.

Cruz, R., Harasawa, H., Lal., Murari., Wu, S., Anokhin, Y., Punsalmaa, B., Honda, Y., Jafari, Mostafa, Li, C. and Ninh, N. 2007. Asia. Climate change 2007: Impacts, adaptation and vulnerability. Contribution of Working Group II to the Fourth Assessment Report of the Intergovernmental Panel on Climate Change. 469-506.

FAO, 2008. Climate change and food security: a framework document. Food and Agriculture Organization, Rome.

Johnston, A. E. 1986. Soil organic matter, effects on soils and crops. Soil Use and Management, 2(3): 97-105.

Kalpana, P., Selva Preetha, P., Sathya, V. and Ramasubramaniyan, M.R. 2019. Assessment of soil fertility status for sustainable agricultural production in Chithamur Block, Kanchipuram District, Tamil Nadu, India. Indian Journal of Pure \& Applied Biosciences, 7(6): 340-350.

Khadka, D., Lamichhane, S., Khan, S., Joshi, S. and Pant, B.B. 2016. Assessment of soil fertility status of Agriculture Research Station,
Belachapi, Dhanusha, Nepal. Journal of Maize Research and Development, 2(1): 43-57.

Kumar, S., Tewari, S.K. and Singh, S.S. 2011. Effect of sources and levels of sulphur and spacing on the growth, yield and quality of spring sunflower (Helianthus annuus). Indian Journal of Agronomy, 56(3): 242-246.

Mokolobate, M. and Haynes, R. 2002. Comparative liming effect of four organic residues applied to an acid soil. Biology and Fertility of Soils, 35(2): 79-85.

Methe, B.A., Nelson, K.E., Pop, M., Creasy, H.H., Giglio, M.G., Huttenhower, C., Gevers, D., Petrosino, J.F., Abubucker, S., Badger, J.H. and Chinwalla, A.T. 2012. A framework for human microbiome research. Nature, 486(7402): p.215.

Pandiaraj, T., Srivastava, P. P. and Susmita Das, S. A. 2017. Evaluation of soil fertility status for soil health card in various tasar growing fields of Bihar and Jharkhand States, India. Int. J Curr. Microbiol. App. Sci., 6(4), 1685-1693.

Raghunatha Reddy, R.L., Shankarappa, T. H., Shankar Reddy Kolle and Satish, M. V. 2019. Review of trends in soil fertility research (20072016) using scopus database. Communications in Soil Science and Plant Analysis, 50(8): 1063-1080.

Ramamoorthy, B. and Bajaj, J. C. 1969. Available nitrogen, phosphorus and potassium status of Indian soils. Fertiliser News.

Shiao, T., Maddocks, A., Carson, C. and Loizeaux, E. 2015. Maps explain India's growing water risks. World Resources Institute, 26.

Singh, R. P. and Mishra, S. K. 2012. Available macro nutrients (N, P, K and $\mathrm{S}$ ) in the soils of Chiraigaon block of district Varanasi (UP) in relation to soil characteristics. Indian Journal of Scientific Research, 97-101.

Tandon, H. L. S. 2005. Methods of Analysis of Soils, Plants, Waters, Fertilisers \& Organic Manures. Fertiliser Development and Consultation Organisation. 